\title{
Are Maintaining Menstrual Hygiene and usage of Sanitary Napkin being Important for Adolescent Girls?
}

\author{
Vasanthi R, and Manju Bala Dash ${ }^{\star}$ \\ Professoer, Department of OBG, MTPG \& RIHS, Puducherry, India
}

\section{Article Info}

\author{
*Corresponding author: \\ Manju Bala Dash \\ Professor \\ Department of OBG, MTPG \& RIHS \\ Puducherry \\ India \\ E-mail: vasi1592@gmail.com
}

Received: January 4, 2019

Accepted: January 12, 2019

Published: January 18, 2019

Citation: Vasanthi $\mathrm{R}$, Dash MB. Are Maintaining Menstrual Hygiene and usage of Sanitary Napkin being Important for Adolescent Girls? Madridge J Intern Emerg Med. 2019; 3(1): 101-104.

doi: 10.18689/mjiem-1000123

Copyright: (c) 2019 The Author(s). This work is licensed under a Creative Commons Attribution 4.0 International License, which permits unrestricted use, distribution, and reproduction in any medium, provided the original work is properly cited.

Published by Madridge Publishers

\begin{abstract}
Background: Menstrual hygiene continues to be amongst the most challenging development issues today. Not only do deep taboos, myths and misinformation create the illusion, but girls often lack access to basic facilities like sanitary pads which are necessary for good menstrual hygiene management (MHM).
\end{abstract}

Aim: This study was designed to assess the practice of menstrual hygiene and usage of sanitary napkin during menstruation among adolescent girls.

Subjects and Methods: A descriptive study was conducted among adolescent girls in selected college at Puducherry. Sample size was 100, selected through purposive sampling. The approach used was Quantitative approach and design was descriptive design. Researcher made questionnaire contained three sections i.e., demographic variables, questions related to practice during menstruation and usage of sanitary napkin respectively.

Result: The major findings of the study, $19 \%$ had Poor practice regarding menstrual hygiene, $66 \%$ had Moderate practice whereas $15 \%$ had Good practice regarding menstrual hygiene. Regarding menstrual bleeding management, $98 \%$ of them was using sanitary napkin whereas $2 \%$ of them using clothes to absorb during menstruation. Among the samples, $99 \%$ of them getting napkin from their own expense whereas $1 \%$ was using government free supply napkin. Regarding cost, $64 \%$ of them were purchasing napkin between 20 and 40 rupees, $27 \%$ of them was purchasing between 40 and 60 rupees, $8 \%$ of them was purchasing above 60 rupees.

Conclusion: The study revealed the practice regarding menstrual hygiene was moderate among the adolescent girls who were studying nursing course. Hence, it is necessary to impart knowledge about menstrual hygiene to adolescent girls which was gathered from this study.

Keywords: Practice; Menstrual Hygiene; Sanitary Napkin; Adolescent Girls.

\section{Introduction}

Menstruation is a spectacle unique to females. In India, limited access to products of sanitary cleanliness and lack of safe sanitary services could increase the probability of resorting to unhygienic practices to manage menstruation [1]. Menstrual hygiene management remains a taboo in many communities in many countries [2].

Adolescent girls constitute a susceptible group, particularly in India. Despite the prominence of the traditional attention to "coming of age", very little is told about the actual facts of menstruation. Much of the data is imparted in form of restrictions [3].

The issue of menstrual hygiene is incompetently acknowledged and has not received proper attention. Use of sanitary pads and washing the genital area are important practices to keep the menstrual hygiene. Unhygienic menstrual practices can affect the 
health of the girls and there is an increased susceptibility to reproductive tract infections and pelvic inflammatory diseases and other complications [4].

Among the total population (1205.6 million), the population of adolescent (10-19 years) is 236.5 that is $19.6 \%$ whereas the adolescent population of India is higher than China (14.1\%), USA (13.8), Indonesia (16.8), Brazil (17.3) [5].

"Sanitary Protection: Every Woman's Health Right", a study by AC Nielsen concluded that out of India's female population ( 355 million) only $12 \%$ use sanitary napkins where as other women depend on different alternatives like un or rugs, ashes and husk sand. Some Grave women diseases such as Reproductive Tract Infection (RTI) is $70 \%$ more commonly visible among these women. Studies on this topic reveal that the utmost barrier of using sanitary napkin is its high cost. In an investigation, around $70 \%$ of women in India say that their family can't afford to buy them. Rs 150 scheme for each girl has launched in 2012 by Union Health Ministry to increase access, affordability and use of sanitary napkins among adolescent girls in rural areas. Under this scheme, packs which contain six SNs are provided to Below Poverty Line (BPL) girls at a funded cost of Re 1 per pack. Girls in the Above Poverty Line (APL) category need to pay Rs 6 per pack of sanitary napkins, which is again very nominal [6].

\section{Objectives}

- To assess the practice regarding menstrual hygiene among adolescent girls.

- To assess about the practice of usage of sanitary napkin during menstruation among adolescent girls.

- To associate the practice with the selected demographic variables.

\section{Methodology}

Research approach is the basic procedure for conducting the study, the present study aimed at assessing the practice of achieve the objectives, a quantitative research approach was found to be appropriate. Research design used for this study is a descriptive study (non-experimental) and research variables are practice of menstrual hygiene and usage of sanitary napkin. The study was conducted in Mother Theresa Post Graduate and Research Institute of Health Sciences. The population comprise of student belonging to the age group of 17-19 years adolescent girls studying in B.Sc. nursing in Mother Theresa Post Graduate and Research Institute of Health Sciences. The adolescent girls were selected from the Mother Theresa Post Graduate and Research Institute of Health Sciences, Puducherry. The sample size comprised of 100 adolescent girls. Sampling technique is a process of selection of portion of the population to represent the entire population. Purposive sampling technique was used for this study; the age group of 17-19 years of adolescent girls was selected from the Mother Theresa post graduate and research institute of health sciences, Indira nagar, Puducherry. Inclusion criteria of sample were [1]. The students who were in menstrual hygiene and usage of sanitary napkin. In order to

age group of 17-19 years [2]. The adolescent girls who are present at the time of data collection [3]. Students who are willing to participate. The tool description was divided into three sections. Section A: This section contains demographic variables of adolescent girls including age, course, religion, residence, family type, economic status of family, hosteller or not, menstruation (regular or not), age at menarche and source of information about menstrual hygiene. Section B: This section contains assessment practice of students regarding menstrual hygiene, closed ended questionnaire (multiple choice questions) consists of 10 questions, a score of one mark is given to every correct answer and zero is given for wrong answers. In that questions, scoring given to evaluate the practice levels of adolescent girls. Out of 12 questions, scoring given as 1 to 4 marks was considered as poor practice, 5 to 7 marks was considered as moderate practice, 8 to 10 marks was considered as good practice. Section C: This section contains questions related to usage of sanitary napkin among adolescent girls during menstruation (multiple choice questions) consists of 11 questions. Data collection procedure include prior permission was obtained from the Principal of Mother Theresa Post Graduate and Research Institute of Health Sciences, Indira nagar, Puducherry. The study was done for one week; the period of data collection was on 19.03.2018 from the students of B.SC. nursing $1^{\text {st }}$ and $2^{\text {nd }}$ year of Mother Theresa Post Graduate and Research Institute of Health Sciences, Indira nagar, Puducherry.

\section{Results}

The results describe that majority of $53 \%$ of adolescent girls belongs to the age group of 18 years, $94 \%$ of girls belongs to the religion of Hindu, $61 \%$ adolescent girls residing in Urban area, $48 \%$ of adolescent girls attained menarche by the age of 13 years, $87 \%$ of the adolescent girls present in the nuclear type, $70 \%$ of adolescent girls belongs to middle class family, $65 \%$ of adolescent girls staying in their home than hosteller, $87 \%$ of adolescent girls having regular menstruation, the source of information gained about menstruation by the girls are mostly $62 \%$ from elders (Table 1 ).

The major findings of the study, $19 \%$ had Poor practice regarding menstrual hygiene, $66 \%$ had Moderate practice whereas $15 \%$ had Good practice regarding menstrual hygiene (Figure 1).

Table 1. Distribution of demographic variables of the adolescent girls in the study $(\mathrm{N}=100)$.

\begin{tabular}{|l|l|c|}
\hline Demographic Variables & Distribution & Percentage (\%) \\
\hline \multirow{3}{*}{ Age } & 17 years & 11 \\
\cline { 2 - 3 } & 18 years & 53 \\
\cline { 2 - 3 } Year of Course & 19 years & 36 \\
\hline \multirow{3}{*}{ Religion } & $1^{\text {st }}$ year nursing & 49 \\
\cline { 2 - 3 } & $2^{\text {nd }}$ Year Nursing & 51 \\
\hline \multirow{2}{*}{ Residence } & Hindu & 94 \\
\cline { 2 - 3 } & Christian & 4 \\
\hline \multirow{2}{*}{ Type of Family } & Muslim & 2 \\
\hline \multirow{3}{*}{ Income } & Rural & 39 \\
\cline { 2 - 3 } & Urban & 61 \\
\hline & Joint & 87 \\
\cline { 2 - 3 } & Nuclear & 2 \\
\hline & High & 28 \\
\cline { 2 - 3 } & Middle & \\
\cline { 2 - 3 } & Low & \\
\hline
\end{tabular}




\begin{tabular}{|l|l|c|}
\hline \multirow{3}{*}{ Stay } & Day scholar & 65 \\
\cline { 2 - 3 } & Hostellers & 35 \\
\hline \multirow{5}{*}{ Denstruation } & Irregular menses & 12 \\
\cline { 2 - 3 } & Regular menses & 88 \\
\hline \multirow{5}{*}{ Age of Menarche } & Elders & 62 \\
\cline { 2 - 3 } & Health professionals & 23 \\
\cline { 2 - 3 } & Teachers & 13 \\
\cline { 2 - 3 } & Media & 2 \\
\hline & 10 years & 1 \\
\cline { 2 - 3 } & 11 years & 22 \\
\cline { 2 - 3 } & 12 years & 48 \\
\cline { 2 - 3 } & 13 years & 19 \\
\cline { 2 - 3 } & 14 years & 7 \\
\cline { 2 - 3 } & 15 years & \\
\hline
\end{tabular}

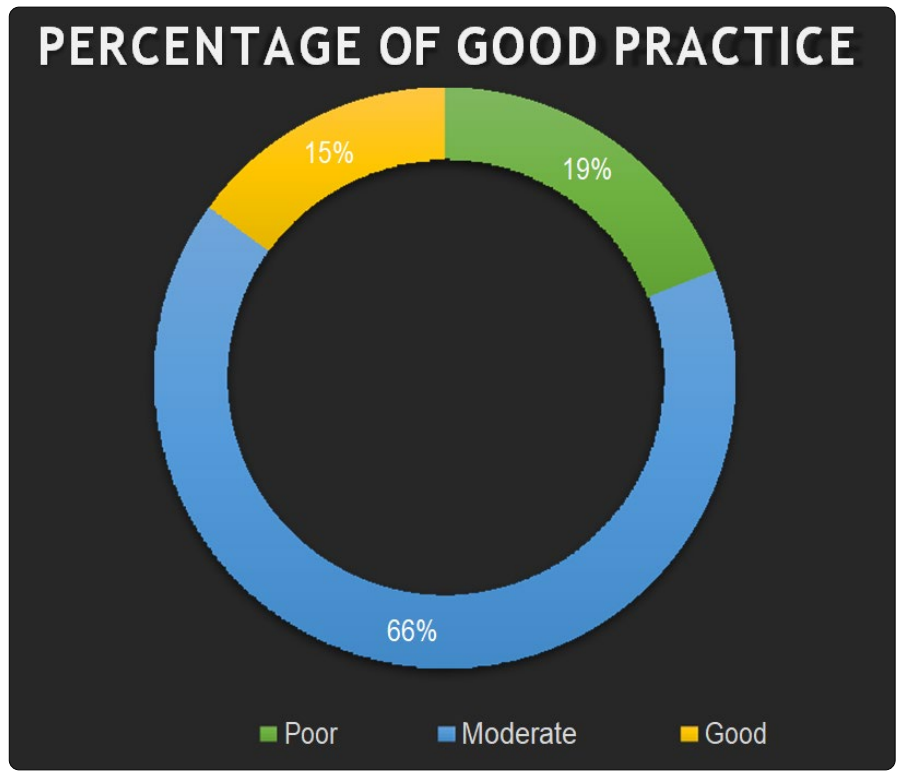

Figure 1. Distribution of level of practice on menstrual hygiene among adolescent girls.

The assessment of usage of sanitary napkin during menstruation among adolescent girls found $98 \%$ of adolescent girls are using sanitary napkin on a regular basis to manage their bleeding during menstruation whereas $2 \%$ of them were using clothes. $57 \%$ of adolescent girls were using Stayfree product as a sanitary napkin, $36 \%$ of adolescent girls were using whisper product as a sanitary napkin whereas $2 \%$ of girls were using sofy product and $5 \%$ of girls are using other products as a sanitary napkin. $64 \%$ of adolescent girls are using between 20 and 40 rupees to cost for their napkin every month, $27 \%$ of adolescent girls are using between 40 and 60 rupees to cost for their napkin every month, $8 \%$ of adolescent girls are using napkin which cost above 60 rupees to cost for their napkin every month and $1 \%$ of them are using government napkin as a free supply. Regarding expense of sanitary napkin, $99 \%$ of adolescent girls are buying napkin from their money whereas $1 \%$ of adolescent girls are using government free supply sanitary napkin.

Regarding satisfaction $36 \%$ of adolescent are not satisfied with Whisper product, $23 \%$ of adolescent girls are not satisfied with Stayfree product, $10 \%$ of adolescent girls are not satisfied with carefree product and $31 \%$ of girls are satisfied with any of the sanitary napkin products. The reason for dissatisfaction, $32 \%$ were not satisfied due to reduced absorption, $30 \%$ were not satisfied due to presence of deodorant, $17 \%$ were not satisfied due to more chemical in napkin whereas $21 \%$ had no issues with sanitary napkins. Among the side effects due to the usage of sanitary napkin, $39 \%$ of girls had itches, $4 \%$ of them had rashes, and $3 \%$ of them had redness whereas $6 \%$ of them had all the above side effects. $48 \%$ of them had no side effects due to napkin. Regarding infection arises because of usage of absorbent, $29 \%$ of them had infection due to the usage of sanitary pads, $38 \%$ of them had infection due to the usage of clothes as an absorbent, $27 \%$ of them had no infection because of their absorbents.

Table 2. Association of results of practice regarding menstrual hygiene with selected demographic and obstetric variables among adolescent girls.

\begin{tabular}{|c|c|c|c|}
\hline Demographic variables & Distribution & Percentage (\%) & $x^{2}$ \\
\hline \multirow{3}{*}{ Age } & 17 years & 11 & \multirow{3}{*}{0.824} \\
\hline & 18 years & 53 & \\
\hline & 19 years & 36 & \\
\hline \multirow{2}{*}{ Year of Course } & $1^{\text {st }}$ year nursing & 49 & \multirow{2}{*}{$\begin{array}{c}0.594 \\
\text { N.S. }\end{array}$} \\
\hline & $2^{\text {nd }}$ year nursing & 51 & \\
\hline \multirow{3}{*}{ Religion } & Hindu & 94 & \multirow{3}{*}{$\begin{array}{c}0.013 \\
S^{*}\end{array}$} \\
\hline & Christian & 4 & \\
\hline & Muslim & 2 & \\
\hline \multirow{2}{*}{ Residence } & Rural & 39 & \multirow{2}{*}{$\begin{array}{c}0.031 \\
S^{*}\end{array}$} \\
\hline & Urban & 61 & \\
\hline \multirow{2}{*}{ Type of Family } & Joint & 13 & \multirow{2}{*}{$\begin{array}{c}0.114 \\
\text { N.S. }\end{array}$} \\
\hline & Nuclear & 87 & \\
\hline \multirow{3}{*}{ Income } & High & 2 & \multirow{3}{*}{$\begin{array}{l}0.487 \\
\text { N.S. }\end{array}$} \\
\hline & Middle & 70 & \\
\hline & Low & 28 & \\
\hline \multirow{2}{*}{ Stay } & Day scholar & 65 & \multirow{2}{*}{$\begin{array}{c}0.540 \\
\text { N.S. }\end{array}$} \\
\hline & Hostellers & 35 & \\
\hline \multirow{2}{*}{ Menstruation } & Irregular menses & 12 & \multirow{2}{*}{$\begin{array}{l}0.987 \\
\text { N.S. }\end{array}$} \\
\hline & Regular menses & 88 & \\
\hline \multirow{4}{*}{ Details Gathered } & Elders & 62 & \multirow{4}{*}{$\begin{array}{c}0.015 \\
S^{*}\end{array}$} \\
\hline & Health professionals & 23 & \\
\hline & Teachers & 13 & \\
\hline & Media & 2 & \\
\hline \multirow{6}{*}{ Age of Menarche } & 10 years & 1 & \multirow{6}{*}{$\begin{array}{c}0.05 \\
\mathrm{~S}^{*}\end{array}$} \\
\hline & 11 years & 3 & \\
\hline & 12 years & 22 & \\
\hline & 13 years & 48 & \\
\hline & 14 years & 19 & \\
\hline & 15 years & 7 & \\
\hline
\end{tabular}

The association of level of practice during menstruation with selected demographic and obstetric variables showed no significant relationship with Age, Course of Study, Type of Family, Stay of Girls, Regularity of Menstruation ( $p>0.05$ ). But Residence, Religion, Gathering of Information, Age of Menarche showed significant relationship with the level of practice of adolescent girls $(p<0.05)$ (Table 2$)$.

\section{Discussion}

The result of the present study showed that majority of the study participants residing in urban area, 13 years as Age of Menarche. The present study result supported with the study conducted by Omidvar $S$ et al., Karnataka, India who reported most of the adolescent girls got menarche at the age of 13 , residing in urban area [7].

The result of the present study showed that majority of adolescent girls had gained information from elders. The present study result was supported by the study conducted by Gandotra N et al., Uttarkhand, India who reported majority of participants knew about menstruation from mothers [8]. 
The result of the present study showed that majority of adolescent girls had moderate practice during menstruation. The present study result was contradicted by the study conducted by Gandotra N et al., Uttarkhand, India who reported majority of participants knew about menstruation from mothers and showed adolescent girls had good practice during menstruation [8].

The result of the present study showed that majority of adolescent girls used sanitary napkin. The present study result was supported by the study conducted by Gandotra $\mathrm{N}$ et al., Uttarkhand, India who reported majority of participants were used sanitary pad instead of cloths [8].

\section{Conclusion}

The study revealed that the practice regarding menstrual hygiene was moderate among the adolescent girls. The usage of sanitary napkin was maximum irrespective of economic status. The government supply napkin usage was very low. Hence, there is less efficient supply of government napkin supply.

\section{Recommendation}

Based on the study findings and personal experience of the investigator during the study, the following recommendations are made:

A similar study may be undertaken by increasing the sample size to generalize the findings.

A comparative study may be conducted with different age groups.

A study can be conducted to evaluate the effectiveness peer to peer education regarding management of menstrual hygiene.

Similar type of studies can be conducted to working women and women with reproductive infections and cancer as retrospective study to generalize the findings.

\section{References}

1. Yadav RN, Joshi S, Poudel R, Pandeya P. Knowledge, Attitude and Practice on menstrual hygiene management among school adolescents. J Nepal Health Res Counc. 2018; 15(3): 212-216.

2. Upashe SP, Tekelab T, Mekonnen J. Assessment of Knowledge and practice of menstrual hygiene among high school girls in Western Ethiopia. BMC Women's Health. 2015; 15: 84. doi: 10.1186/s12905-0150245-7

3. Shoor P. A study of knowledge, attitude and practices of menstrual health among adolescent school girls in urban field practices area of medical college, Tumkur. Indian Journal of Health Sciences and Biomedical Research (KLEU). 2017; 10(3): 249-255. doi: 10.4103/kleuhsj.ijhs_375_16

4. Ministry of Home Affairs. Office of the Registrar General \& Census Commissioner, India. Government of India.

5. Khanna A, Goyal RS, Bhawsar R. Menstrual practices and reproductive problems: a study of adolescent girls in Rajasthan. $J$ Health Management. 2005; 7(1): 91-107. doi: 10.1177/097206340400700103

6. Sharma $P$, Singh $N$, Tempre A, Sharma S. Knowledge, Practice and restrictions related to menstruation in young girls: a study from North India. International Journal of Community Medicine and Public Health. 2018; 5(8): 3340-3344. doi: 10.18203/2394-6040.ijcmph20183058

7. Omidvar S, Miri FN, Bakhtiari A, Begum K. A study on menstruation of Indian adolescent girls in an urban area of south India. J Family Med Prim Care. 2018; 7(4): 698-702. doi: 10.4103/jfmpc.jfmpc_258_17

8. Gandotra N, Pal R, Maheshwari S. Assessment of Knowledge and practices of menstrual hygiene among urban adolescent girls in north India. International Journal of Reproduction, Contraception, Obstetrics and Gynecology. 2018; 7(7): 2825-2828. doi: 10.18203/2320-1770. ijrcog20182889

9. Ricci SS. Essentials of Maternity, Newborn and Women's Health Nursing. 3rd edition. Philadelphia: Lippincott Williams \& Wilkins, 2013.

10. Klossner NJ, Hatfield NT. Introductory Maternity \& Paediatric Nursing. 2nd edition. Philadelphia: Lippincott Williams \& Wilkins, 2010. 